\title{
Plasmon mediated decomposition of brominated nucleobases on silver nanoparticles - A surface enhanced Raman scattering (SERS) study ${ }^{\star}$
}

\author{
Anushree Dutta, Robin Schürmann ${ }^{\mathrm{a}}$, and Ilko Bald \\ Institute of Chemistry, Physical Chemistry, University of Potsdam, Karl-Liebknecht-Str. 24-25, 14476 Potsdam, Germany
}

Received 28 February 2019 / Received in final form 26 June 2019

Published online 28 January 2020

(c) The Author(s) 2020. This article is published with open access at Springerlink.com

\begin{abstract}
The localized surface plasmon resonances (LSPRs) of silver nanoparticles (AgNPs) give rise to the generation of so called hot electrons and a high local electric field enhancement, which enable an application of AgNPs in different fields ranging from catalysis to sensing. Hot electrons generated upon the decay of LSPRs are transferred to molecules adsorbed on the surface of the NPs and trigger chemical reactions via dissociative electron attachment (DEA). Herein, we report on the hot electron induced decomposition of the brominated nucleobases - 8-bromoadenine, 8-bromoguanine, 5-bromocytosine and 5-bromouracil on laser illuminated AgNP surfaces. Surface enhanced Raman scattering (SERS) spectra of all canonical nucleobases and their brominated analogues have been recorded at different laser illumination times, and for the very first time we present SERS measurements of 8-bromoguanine and 5-bromocytosine. Reaction products have been identified by their vibrational fingerprint revealing the cleavage of the carbon bromide bond in all cases even under mild illumination conditions. These results indicate that the wellknown reactions from DEA experiments in the gas phase (i) are also taking place on nanoparticle surfaces under ambient conditions, (ii) can be monitored by SERS, and (iii) are also of importance in analytical SERS applications involving electrophilic molecules, as the bands originating from reaction products need to be identified.
\end{abstract}

\section{Introduction}

Collective oscillations of the conduction band electrons in noble metal nanoparticles (NPs), so called localized surface plasmon resonances (LSPRs), are excited by the alternating electric field of incident visible or near-infrared light. LSPRs enhance the local electric field in the vicinity of the NPs. This effect is exploited in surface enhanced Raman scattering (SERS), where the initial Raman signal of molecules on the NP surface is enhanced by the forth power of the electric field enhancement $\left|E / E_{0}\right|[1]$. The combination of the high signal enhancement and the specificity due to the vibrational fingerprint of the molecule enables analytical applications using SERS [2-4]. For analytical applications it is crucial to differentiate between the signals of the analyte molecules and signals of reaction products generated during the measurement process. Such reactions can be initiated by an electron transfer, as

\footnotetext{
* Contribution to the Topical Issue "Dynamics of Systems on the Nanoscale (2018)", edited by Ilko Bald, Ilia A. Solov'yov, Nigel J. Mason and Andrey V. Solov'yov

a e-mail: rschuerm@uni-potsdam.de
}

besides the scattering process utilized in SERS, LSPRs can also decay in a non-radiative pathway by forming electron-hole pairs [5-8]. These electrons mainly generated by Landau damping at the surface of the NPs can be further transferred into an unoccupied molecular orbital of adsorbed molecules and trigger reactions therein $[9,10]$. As the energy of these electrons exceeds for a short timescale the thermal equilibrium of the AgNP lattice, they are typically referred to as hot electrons [5]. Alternatively, also a direct electron transfer from the NPs into the molecular orbitals by a chemical induced damping of the LSPRs is possible [11]. The occupation of a formerly unoccupied molecular orbital results in the formation of a transient negative ion, which can decay into a negative and one or more neutral fragments via dissociative electron attachment (DEA) [12]:

$$
\mathrm{AB}+\mathrm{e}^{-} \rightarrow \mathrm{AB}^{-\#} \rightarrow \mathrm{A}^{-}+\mathrm{B}
$$

DEA to molecules in the gas phase is typically studied using crossed molecular-electron beam setups and mass spectrometry [12] revealing a high energy and bond selectivity of the DEA process $[13,14]$. The adsorption of molecules on a surface strongly influences the DEA process, e.g. due to trapping of the negative charge in image 
potential states $[15,16]$. Even though the precise energy of the transferred electrons in hot electron induced reactions remains unknown, it is limited by the initial photon energy $(<3 \mathrm{eV})$ and typically close to the Fermi energy [8]. In consequence, only low-lying resonances are involved in the formation of the transient negative ions. Within this work, we are studying the hot electron induced decomposition of brominated nucleobase analogues on AgNP aggregates. Bromoadenine (BrA) [17] and bromouracil (BrU) [18] in the gas phase show a high reactivity towards low energy electrons (LEEs) with an energy close to $0 \mathrm{eV}$ resulting in the cleavage of the carbon bromide bond leaving the residual molecule intact. For bromocytosine (BrC) and bromoguanine (BrG) equivalent reaction pathways are postulated [19-21]. On the contrary, DEA measurements in the gas-phase on the nucleobases adenine [22], cytosine [23], guanine [24] and thymine [23] do not exhibit resonant bond cleavage upon attachment of LEEs close to $0 \mathrm{eV}$. In these cases the most abundant fragmentation channel is the abstraction of an hydrogen atom induced by electrons with an energy around $1 \mathrm{eV}$ [22-24]. Recently, the breaking of the $\mathrm{C}-\mathrm{Br}$ bond in $\mathrm{BrU}$ has been observed in the proximity of AuNPs irradiated by intense laser pulses, most likely induced by thermionically emitted LEEs [25]. Moreover, it has been demonstrated for BrA that the electron induced cleavage of the $\mathrm{C}-\mathrm{Br}$ bond can be observed on $\mathrm{AgNPs}$ when illuminated with low intensity continuous wave laser light [26]. Halogenated nucleobases are of special interest due to their strong interaction with LEEs and potential applications as radiosensitizing agents in cancer therapy [27]. In that context is known that the combination of electrophilic radiosensitizers with NPs, as a source of electrons, highly enhances radiation induced DNA damage [28]. Beyond that, metal NPs illuminated by lasers are proposed as a novel therapy in cancer research, the so called photothermal therapy (PTT), where cancer cells are effectively killed due to the elevated temperatures in the vicinity of the NPs [29]. However, in the context of PTT the role of hot electrons has poorly been studied and consequently the application of electrophilic radiosensitizers has not been considered so far. Hence, in the presented work the plasmon mediated reactions of brominated nucleobases have been examined by SERS. The reactions were triggered and tracked by the laser in a confocal Raman microscope setup [30]. Therefore, we have decorated AgNPs with brominated and non-brominated nucleobases and measured their behavior towards hot electrons generated by laser light on the surface of aggregated NPs through SERS in the condensed phase at different illumination times. The vibrational fingerprint of the reaction products has been determined, in order to enable future experiments in more complex environments, which are required to evaluate the potential role of radiosensitizing agents in PTT. Furthermore, a time dependent study for $\mathrm{BrA}$ was carried out to identify the reaction products formed during the dissociative hot electron transfer by monitoring the change in intensity of respective vibrational bands of nucleobases and their brominated analogues.

\section{Experimental section}

\subsection{Chemicals}

Adenine (A), cytosine (C), guanine (G), uracil (U), bromocytosine $(\mathrm{BrC})$, bromoguanine $(\mathrm{BrG})$, bromouracil $(\mathrm{BrU})$, silver nitrate $\left(\mathrm{AgNO}_{3}\right)$ and trisodium citrate were purchased from Sigma Aldrich (Germany). Bromoadenine (BrA) was purchased from Carbosynth (UK). All chemicals were used in Milli-Q filtered water without further purification.

\subsection{AgNP synthesis}

AgNPs were synthesized by citrate reduction method using a modified Lee-Meisel protocol [31]. The glassware was cleaned with aqua regia prior to use. $90 \mathrm{mg}$ of $\mathrm{AgNO}_{3}$ was dissolved in $500 \mathrm{~mL}$ water and the solution was heated up to a rolling boil under reflux condition in a $1000 \mathrm{~mL}$ three neck round bottom flask $\left(T=125^{\circ} \mathrm{C}\right)$. This was followed by addition of $10 \mathrm{~mL}$ of $4 \%$ aqueous trisodium citrate to the boiling solution rapidly using a syringe under stirring condition (600 rpm). The boiling was further continued for 1 more hour. Subsequently, the solution was cooled down to room temperature and stored at $4{ }^{\circ} \mathrm{C}$ for further experiments.

\subsection{UV-Vis spectroscopy}

UV-Vis-extinction spectra were recorded with a Nanodrop 2000 from Fisher Scientific.

\subsection{Atomic force microscopy (AFM)}

AFM technique was used to determine the size of the AgNPs. A $2 \mu \mathrm{L}$ droplet of AgNPs, which had been washed with MilliQ water, was drop cast on a Si substrate and allowed to air-dry. Next, the size distribution of AgNPs was determined using the height profiles of the particles obtained from AFM images. The AFM images were recorded using a Flex AFM from Nanosurf equipped with Tap150 Al-G $(5 \mathrm{~N} / \mathrm{m}, 150 \mathrm{kHz})$ cantilever in the soft tapping mode. The data processing was performed using the Gwyddion (v 2.48) software.

\subsection{Raman spectroscopy}

Sample preparation: the as synthesized AgNPs were purified by centrifugation prior to use. Briefly, $1 \mathrm{~mL} \mathrm{Ag} \mathrm{NP}$ dispersion was taken and centrifuged at $2000 \mathrm{rcf}$ for $10 \mathrm{~min}$ at $20{ }^{\circ} \mathrm{C}$ and the precipitate was re-dispersed in $1 \mathrm{~mL}$ MilliQ water. To prepare samples for Raman measurements typically $20 \mu \mathrm{L}$ of $0.5 \mathrm{mM}$ solution of three nucleobases (A, G and U) and their brominated analogues (BrA, BrG and BrU) were mixed with $80 \mu \mathrm{L}$ of AgNPs 


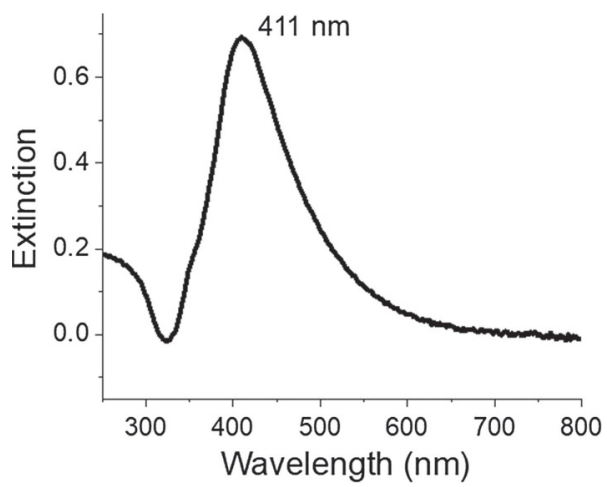

Fig. 1. UV-Vis extinction spectrum of the freshly synthesized AgNPs.

dispersion. In case of $\mathrm{C}$ and $\mathrm{BrC}, 10 \mu \mathrm{L}$ of $0.5 \mathrm{mM}$ were mixed with $90 \mu \mathrm{L}$ of AgNPs dispersion. The $0.5 \mathrm{mM}$ $\mathrm{G}$ and $\mathrm{BrG}$ solutions were made in $\mathrm{NaOH}$, due to their poor water solubility, such that the final concentration of $\mathrm{NaOH}$ was $13 \mathrm{mM}$ and $0.8 \mathrm{mM}$ in the respective solution. The resulting mixture was then allowed to incubate for $1 \mathrm{~h}$ followed by centrifugation at $1000 \mathrm{rcf}$ for $10 \mathrm{~min}$ at $20{ }^{\circ} \mathrm{C}$. The precipitate obtained after centrifugation was re-dispersed in $20 \mu \mathrm{L}$ Milli-Q water and $10 \mu \mathrm{L}$ dispersion was drop cast on a cleaned Si wafer and allowed to air-dry overnight.

Raman measurements: Raman measurements of nucleobase coated AgNPs were carried out using a WITec alpha300 Raman-microscope with a $532 \mathrm{~nm}$ excitation laser and $10 \times$ objective $(\mathrm{NA}=0.25)$. For all measurements, laser power of $50 \mu \mathrm{W}$ was used. The measurements were carried out in triplicate from different sample area. The normal Raman spectra (NRS) of the solid nucleobase samples were recorded using a $785 \mathrm{~nm}$ laser with $1 \mathrm{~mW}$ power ( $5 \mathrm{~s}$ integration time, 5 accumulations).

Data processing: the SERS spectra were analyzed and processed using Origin 9.1 software.

\section{Results and discussion}

Figure 1 shows the extinction spectrum of the freshly synthesized citrate stabilized AgNPs. The extinction maximum located at $411 \mathrm{~nm}$ with a full-width at half maximum of $103 \mathrm{~nm}$ indicates the formation of AgNPs with an average diameter of $30 \mathrm{~nm}$ [32].

The size of the NPs was also determined by AFM measurements from the height profile of dried AgNPs imaged on a Si wafer revealing a diameter, $d=(34 \pm 9) \mathrm{nm}$. Figure 2 shows an AFM image of the AgNPs and the size distribution of the as synthesized AgNPs in the inset.

In order to monitor the plasmon mediated reactions by SERS, the AgNPs were coated with the nucleobase and their brominated analogues which were then drop cast on a silicon substrate and allowed to air dry. The dried samples formed fractal aggregates of AgNPs, which are known for high optical enhancement [33]. The aggregation process is strongly influenced by the type of the nucleobase $[34,35]$. During the incubation and washing steps the AgNPs tend

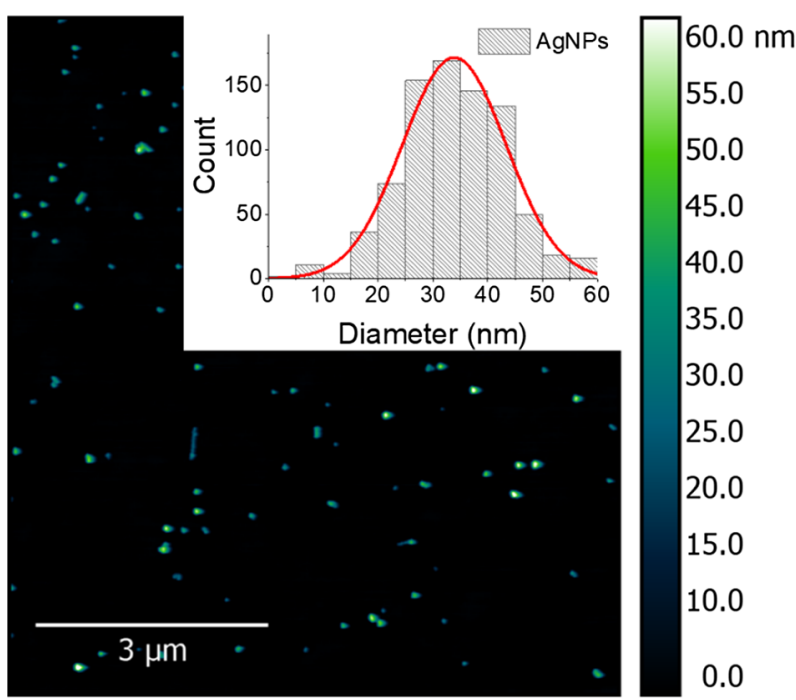

Fig. 2. AFM image of AgNPs on Si Wafer. Inset shows size distribution of as-synthesized AgNPs determined from AFM images fitted with a Gaussian function (red).

to aggregate, as on the one hand the adsorbed nucleobases interact with each other e.g. due to $\pi-\pi^{*}$ stacking interaction and on the other hand the citrate as surface stabilizer is removed $[36,37]$. The latter is crucial to minimize the contributions of the citrate molecules to the Raman signal and also to facilitate adsorption of the nucleobases on the NP surface. In consequence, the AgNP solution gets relatively unstable due to the ligand exchange and needs to be rapidly processed. Therefore, after a final centrifugation step, the nucleobase coated AgNPs are immediately dried on a Si substrate. Figure 3 shows the bright-field microscopic images of all the AgNPs coated with nucleobases and their brominated analogues, revealing a general influence of the nature of nucleobases on the formation process of the SERS substrate. Consequently, in order to ensure reproducible Raman measurements, densely covered areas with a similar contrast in the brightfield microscopic images have been chosen for all measurements. It is to be mentioned at this point that a direct quantification and comparison between the observed reactions is challenging. In order to quantify the measurements with the different nucleobases, their Raman cross-section, the local signal enhancement on the nanoscale and the concentration, position and orientation of the adsorbed nucleobases in the reactive regions [38] need to be determined.

Surface enhanced Raman scattering spectra of the AgNP samples coated with halogenated nucleobases were recorded at different illumination times using a $532 \mathrm{~nm}$ laser $(50 \mu \mathrm{W})$ focused with a $10 \times / 0.25 \mathrm{NA}$ objective to a spot with approximately $2.6 \mu \mathrm{m}$ diameter. Mild illumination conditions have been chosen in order to avoid effects due to electric fields, which are even in the hot spots well below $10^{7} \mathrm{~V} / \mathrm{m}$, and moreover minimize the heating of the substrate. Photolysis of the molecules is unlikely as well, since the molecules do not absorb light in the visible range and two-photon processes are not relevant at the present photon densities [35]. 

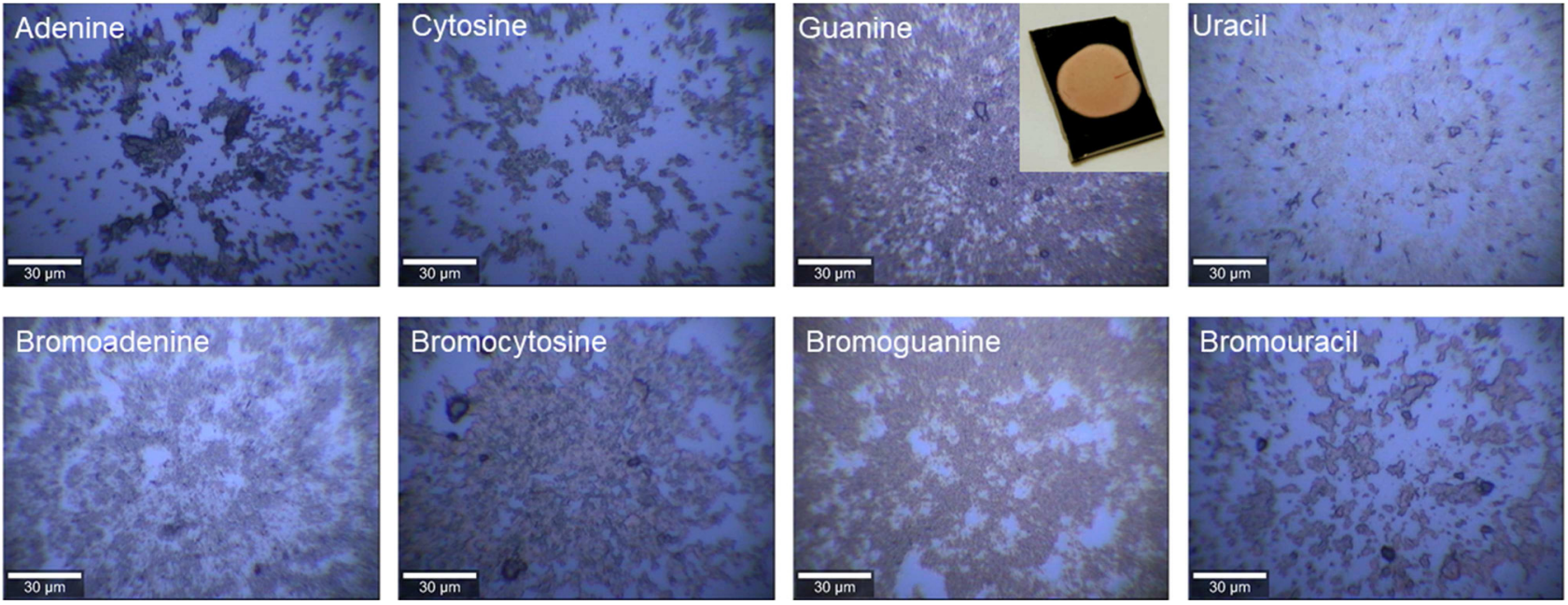

Fig. 3. Brightfield microscopic images of the aggregated AgNPs capped with different nucleobase analogues using a Nikon E-Plan $50 \times / \mathrm{NA}=0.75$ objective. Inset in the guanine image shows a digital image of guanine capped AgNPs dried on a Si wafer.

\subsection{Bromoadenine and adenine}

The results for BrA reported herein are in accordance with measurements under slightly different experimental conditions published previously [26]. Figure 4 clearly reveals the vibrational band at $770 \mathrm{~cm}^{-1}$ assigned to the ring breathing mode of $\mathrm{BrA}$ at the beginning of the illumination $(1 \mathrm{~s})$ of the sample. On the other hand, the SERS spectrum recorded after $100 \mathrm{~s}$ of laser illumination, shows a sharp decrease in the intensity of the BrA ring breathing mode, and at the same time peaks associated with the vibrational fingerprint of adenine appear clearly. Table 1 shows all observed bands in the SERS spectrum of BrA on AgNPs which have been compared with the NRS spectrum of solid BrA. The peak assignment has been done with respect to the vibrational frequencies determined by Chen et al. using density functional theory (DFT) calculations [39].

The most prominent band observed after $100 \mathrm{~s}$ illumination time was due to the ring breathing mode of adenine at $739 \mathrm{~cm}^{-1}$. Further prominent new bands, clearly associated with the formation of $\mathrm{A}$ are observed at $638 \mathrm{~cm}^{-1}$, $965 \mathrm{~cm}^{-1}$ and at $1341 \mathrm{~cm}^{-1}$. The assignments for all the observed Raman bands are shown in Table 1. Slight deviations in the wavenumbers are observed for the rising A peaks during decomposition of $\mathrm{BrA}$ compared to the SERS signal of only A recorded on AgNPs as reported in Table 1. These deviations may be explained by the close overlap of A peaks with the BrA peaks in the SERS spectra or due to the possible different orientation of the molecules on the NP surface. Moreover, also modifications of the A molecule such as A radicals or charged species are possible. During the reaction process, the bands due to BrA underwent a decrease in intensity, particularly pronounced at the ring breathing mode at $770 \mathrm{~cm}^{-1}$, while the vibrational bands due to A increase. Even at a comparatively low laser power and within $1 \mathrm{~s}$ of laser illumination, the SERS spectra showed Raman peaks, which originated from the vibrational modes of A on the AgNPs surface.

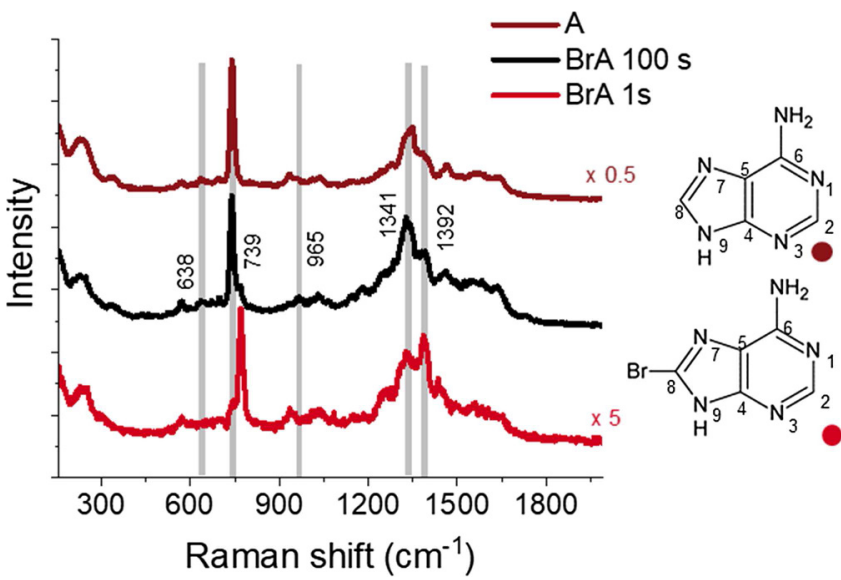

Fig. 4. SERS spectra of BrA adsorbed on AgNPs after $1 \mathrm{~s}$ (light red) and $100 \mathrm{~s}$ (black) of laser illumination in a confocal Raman microscope and SERS spectrum of A on AgNPs (dark red) is shown as a control. Laser wavelength: $532 \mathrm{~nm}$, laser power: $0.05 \mathrm{~mW}$, data acquisition time: $0.4 \mathrm{~s}$, number accumulations: 3. The wavenumbers of the marked Raman bands are determined from the BrA spectrum after $100 \mathrm{~s}$ of laser illumination. Molecular structure of $\mathrm{A}$ and $\mathrm{BrA}$ are presented on the right side.

The A is most likely formed by a dissociative hot electron transfer from the laser illuminated particles:

$$
\operatorname{AgNPs}+h v \rightarrow \mathrm{e}^{-}+h^{+} .
$$

The electron is captured by $\mathrm{BrA}$ and forms a metastable anion, which decays mainly by the cleavage of the $\mathrm{C}-\mathrm{Br}$ bond if the incident electron energy is low [17]:

$$
\mathrm{BrA}+\mathrm{e}^{-} \rightarrow \mathrm{BrA}^{\#-} \rightarrow \mathrm{Br}^{-}+\mathrm{A} .
$$

The reaction was tracked by following the decrease in the intensity of the ring breathing mode of BrA at $770 \mathrm{~cm}^{-1}$ 
Table 1. Raman shifts of NRS and SERS bands of A and BrA observed in the present experiment given in $\mathrm{cm}^{-1}$ and assignment of the bands according to references [39] and [40]. $\omega$ : wagging; $\delta$ : in-plane deformation; $\Delta$ : in-plane ring deformation of skeletal atoms; $\gamma$ : out-of-plane deformation; $\Gamma$ : out-of-plane ring deformation of skeletal atoms; $\alpha$ : scissoring; $\tau$ : torsion; t: twisting; $\nu$ : stretching; r: rocking; Pyr: pyrimidine; Im: imidazol. Atoms are labeled according to Figure 4.

\begin{tabular}{|c|c|c|c|c|c|}
\hline NRS A & SERS A & Assignment [40] & NRS BrA & SERS BrA & Assignment [39] \\
\hline 193 & & $\gamma(\mathrm{C} 6-\mathrm{N} 10)$ & 153 & & $\delta(\mathrm{C} 8-\mathrm{Br}), \delta(\mathrm{C} 6-\mathrm{N} 10), \delta(\mathrm{Pyr})$ \\
\hline 246 & & "Butterfly" mode & 198 & & \\
\hline 333 & & $\Delta(\mathrm{C} 6-\mathrm{C} 5-\mathrm{N} 7)-\Delta(\mathrm{N} 1-\mathrm{C} 6-\mathrm{N} 10)+\Delta(\mathrm{N} 3-\mathrm{C} 4-\mathrm{N} 9)$ & 248 & & $\begin{array}{l}\nu(\mathrm{C} 8-\mathrm{Br}), \quad \delta(\mathrm{C} 6-\mathrm{N} 10), \quad \delta(\operatorname{Im}), \\
\delta(\mathrm{C} 8-\mathrm{Br})\end{array}$ \\
\hline 539 & & $\Delta(\mathrm{N} 1-\mathrm{C} 6-\mathrm{C} 5)+\Delta(\mathrm{C} 2-\mathrm{N} 3-\mathrm{C} 4)$ & 298 & & $\tau(\mathrm{C} 4-\mathrm{C} 5), \gamma(\mathrm{C} 8-\mathrm{Br}), \tau(\mathrm{Pyr}$ ring $)$ \\
\hline 564 & 568 & $\Gamma(\mathrm{N} 1-\mathrm{C} 2-\mathrm{N} 3)+\gamma(\mathrm{C} 2-\mathrm{H})-\gamma(\mathrm{C} 8-\mathrm{H})$ & 372 & & $\begin{array}{l}\Delta(\mathrm{C} 6-\mathrm{N} 10), \nu(\mathrm{C} 8-\mathrm{Br}), \delta(\mathrm{C} 8-\mathrm{Br}) \\
\alpha(\mathrm{Im} \text { ring })\end{array}$ \\
\hline 626 & 641 & $\Delta(\mathrm{C} 4-\mathrm{C} 5-\mathrm{N} 7)-\Delta(\mathrm{C} 4-\mathrm{N} 9-\mathrm{C} 8)+\Delta(\mathrm{N} 1-\mathrm{C} 6-\mathrm{N} 10)$ & 547 & & $\delta$ (Pyr Ring $), \delta(\mathrm{C} 8-\mathrm{Br}), \delta(\mathrm{C} 6-\mathrm{N} 10)$ \\
\hline 727 & 740 & Pyr + Im ring breathing & 596 & 572 & $\begin{array}{l}\tau(\text { Pyr Ring }), \tau(\text { Im Ring }), \gamma(\mathrm{C} 6- \\
\text { N10) }\end{array}$ \\
\hline 801 & & $\omega(\mathrm{NH} 2)$ & 628 & & $\begin{array}{l}\tau \text { (Pyr Ring }), \tau(\text { Im Ring }), \gamma(\mathrm{C} 6- \\
\text { N10) }\end{array}$ \\
\hline 902 & 933 & $\Delta(\mathrm{N} 1-\mathrm{C} 2-\mathrm{N} 3)+\Delta(\mathrm{C} 8-\mathrm{N} 9-\mathrm{C} 5)$ & 757 & 770 & Pyr + Im ring breathing \\
\hline 945 & 957 & $\Delta(\mathrm{N} 7-\mathrm{C} 8-\mathrm{N} 9) ; \gamma(\mathrm{N} 9-\mathrm{H})$ & 894 & & $\delta($ Pyr Ring $), \nu(\mathrm{C} 5-\mathrm{N} 7)$ \\
\hline 1028 & 1035 & $\mathrm{t}(\mathrm{NH} 2) ; \nu(\mathrm{C} 6-\mathrm{N} 1)$ & 913 & & $\delta(\mathrm{Im}), \delta(\mathrm{Pyr}), \nu(\mathrm{C} 8-\mathrm{N} 9)$ \\
\hline 1129 & 1137 & $\begin{array}{l}\delta(\mathrm{C} 8-\mathrm{H}) ; \nu(\mathrm{C} 3-\mathrm{N} 3)+\nu(\mathrm{C} 4-\mathrm{N} 9) \\
\delta-\nu(\mathrm{C} 5-\mathrm{C} 6)-\nu(\mathrm{C} 5-\mathrm{N} 7)\end{array}$ & 984 & 939 & $\begin{array}{l}\mathrm{r}(\mathrm{NH} 2), \nu(\mathrm{C} 6-\mathrm{N} 1) \\
\nu(\mathrm{C} 2-\mathrm{N} 1)\end{array}$ \\
\hline 1166 & & $\begin{array}{l}\delta(\mathrm{C} 8-\mathrm{H})-\delta(\mathrm{N} 9-\mathrm{H}) ; \nu(\mathrm{C} 8-\mathrm{N} 9)+(\mathrm{C} 5-\mathrm{N} 7)-\nu(\mathrm{C} 4- \\
\mathrm{N} 9)-\nu(\mathrm{C} 4-\mathrm{N} 3)-\nu(\mathrm{C} 2-\mathrm{N} 3)\end{array}$ & 1039 & 1031 & $\nu(\mathrm{C} 8-\mathrm{N} 9), \delta(\mathrm{N} 9-\mathrm{H}), \nu(\mathrm{C} 4-\mathrm{N} 9)$ \\
\hline 1252 & 1280 & $\begin{array}{l}\delta(\mathrm{C} 8-\mathrm{H})+\delta(\mathrm{N} 9-\mathrm{H}) ; \nu(\mathrm{C} 2-\mathrm{N} 3)+\nu(\mathrm{C} 8-\mathrm{N} 7)+ \\
\nu(\mathrm{C} 2-\mathrm{N} 1)-\nu(\mathrm{C} 5-\mathrm{N} 7)-\nu(\mathrm{C} 4-\mathrm{N} 9)\end{array}$ & 1148 & & $\begin{array}{l}\delta(\mathrm{N} 9-\mathrm{H}), \quad \nu(\mathrm{C} 4-\mathrm{N} 3), \quad \delta(\mathrm{Im} \quad \text { ring }) \\
\nu(\mathrm{C} 4-\mathrm{N} 9)\end{array}$ \\
\hline 1312 & & $\begin{array}{l}\delta(\mathrm{C} 2-\mathrm{H}) ; \nu(\mathrm{C} 2-\mathrm{N} 3)+\nu(\mathrm{C} 5-\mathrm{N} 7)-\nu(\mathrm{C} 8-\mathrm{N} 7)- \\
\nu(\mathrm{C} 4-\mathrm{N} 9)\end{array}$ & 1176 & & \\
\hline 1336 & 1346 & $\begin{array}{l}\delta(\mathrm{C} 2-\mathrm{H}) ; \nu(\mathrm{C} 2-\mathrm{N} 3)+\nu(\mathrm{C} 5-\mathrm{N} 7)-\nu(\mathrm{C} 8-\mathrm{N} 7)- \\
\nu(\mathrm{C} 4-\mathrm{N} 9)\end{array}$ & 1210 & & \\
\hline 1375 & & $\begin{array}{l}\delta(\mathrm{N} 9-\mathrm{H}) ; \delta(\mathrm{C} 8-\mathrm{H}) ; \nu(\mathrm{C} 8-\mathrm{N} 9)+\nu(\mathrm{C} 4-\mathrm{C} 5)+\nu(\mathrm{C} 2- \\
\mathrm{N} 3)+\nu(\mathrm{C} 6-\mathrm{N} 1)-\nu(\mathrm{C} 5-\mathrm{C} 6)-\nu(\mathrm{C} 2-\mathrm{N} 1)-\nu(\mathrm{C} 4- \\
\mathrm{N} 3)-\nu(\mathrm{C} 8-\mathrm{N} 7)\end{array}$ & 1256 & 1257 & $\begin{array}{l}\nu(\mathrm{C} 5-\mathrm{N} 7), \\
\nu(\mathrm{C} 2-\mathrm{N} 1)\end{array}$ \\
\hline 1422 & & $\begin{array}{l}\delta(\mathrm{N} 9-\mathrm{H}) ; \delta(\mathrm{C} 8-\mathrm{H}) ; \nu(\mathrm{C} 8-\mathrm{N} 9)+\nu(\mathrm{C} 4-\mathrm{C} 5)+\nu(\mathrm{C} 2- \\
\mathrm{N} 3)+\nu(\mathrm{C} 6-\mathrm{N} 1)-\nu(\mathrm{C} 5-\mathrm{C} 6)-\nu(\mathrm{C} 2-\mathrm{N} 1)-\nu(\mathrm{C} 4- \\
\mathrm{N} 3)-\nu(\mathrm{C} 8-\mathrm{N} 7)\end{array}$ & 1294 & & $\nu(\mathrm{C} 2-\mathrm{N} 3), \nu(\mathrm{C} 5-\mathrm{N} 7)$ \\
\hline 1466 & 1464 & $\begin{array}{l}\delta(\mathrm{N} 9-\mathrm{H})-\delta(\mathrm{C} 8-\mathrm{H})+\delta(\mathrm{C} 2-\mathrm{H}) ; \nu(\mathrm{C} 8-\mathrm{N} 9)+\nu(\mathrm{C} 2- \\
\mathrm{N} 1)+\nu(\mathrm{C} 6-\mathrm{N} 1)-\nu(\mathrm{C} 2-\mathrm{N} 3)-\nu(\mathrm{C} 8-\mathrm{N} 7)-\nu(\mathrm{C} 6- \\
\mathrm{N} 10)\end{array}$ & 1330 & 1332 & $\begin{array}{l}\delta(\mathrm{C} 2-\mathrm{H}), \quad \nu(\mathrm{C} 6-\mathrm{N} 10), \quad \nu(\mathrm{C} 8-\mathrm{N} 9) \\
\nu(\mathrm{C} 2-\mathrm{N} 1)\end{array}$ \\
\hline 1486 & & $\begin{array}{l}\alpha(\mathrm{NH} 2) ; \delta(\mathrm{N} 9-\mathrm{H}) \delta(\mathrm{C} 8-\mathrm{H})+\delta(\mathrm{C} 2-\mathrm{H}) ; \nu(\mathrm{C} 4-\mathrm{C} 5) \\
+\nu(\mathrm{C} 2-\mathrm{N} 1)+\nu(\mathrm{C} 6-\mathrm{N} 1)+\nu(\mathrm{C} 8-\mathrm{N} 9) \nu(\mathrm{C} 2-\mathrm{N} 3) \\
\nu(\mathrm{C} 4-\mathrm{N} 9) \nu(\mathrm{C} 8-\mathrm{N} 9)\end{array}$ & 1351 & 1388 & $\delta(\mathrm{N} 9-\mathrm{H}), \nu(\mathrm{C} 4-\mathrm{N} 9), \nu(\mathrm{C} 8-\mathrm{N} 9)$ \\
\hline 1601 & & $\begin{array}{l}\alpha(\mathrm{NH} 2) ; \delta(\mathrm{N} 9-\mathrm{H}) ; \nu(\mathrm{C} 4-\mathrm{C} 5)+\nu(\mathrm{C} 2-\mathrm{N} 1) \nu(\mathrm{C} 5-\mathrm{C} 6) \\
\nu(\mathrm{C} 6-\mathrm{N} 1) \nu(\mathrm{C} 4-\mathrm{N} 3) \nu(\mathrm{C} 2-\mathrm{N} 3)\end{array}$ & 1445 & 1435 & $\nu(\mathrm{C} 8-\mathrm{N} 7)$ \\
\hline \multirow[t]{3}{*}{1615} & 1634 & $\begin{array}{l}\alpha(\mathrm{NH} 2) ; \delta(\mathrm{N} 9-\mathrm{H}) ; \nu(\mathrm{C} 4-\mathrm{C} 5)+\nu(\mathrm{C} 2-\mathrm{N} 1)-\nu(\mathrm{C} 5- \\
\mathrm{C} 6)-\nu(\mathrm{C} 6-\mathrm{N} 1)-\nu(\mathrm{C} 4-\mathrm{N} 3)-\nu(\mathrm{C} 2-\mathrm{N} 3)\end{array}$ & 1454 & & \\
\hline & & & 1494 & 1497 & $\begin{array}{l}\delta(\mathrm{C} 2-\mathrm{H}), \quad \nu(\mathrm{C} 6-\mathrm{N} 1), \quad \nu(\mathrm{C} 6-\mathrm{N} 10), \\
\delta(\mathrm{NH} 2)\end{array}$ \\
\hline & & & 1524 & 1553 & $\Delta(\mathrm{NH} 2), \nu(\mathrm{C} 4-\mathrm{C} 5), \nu(\mathrm{C} 5-\mathrm{C} 6)$ \\
\hline
\end{tabular}

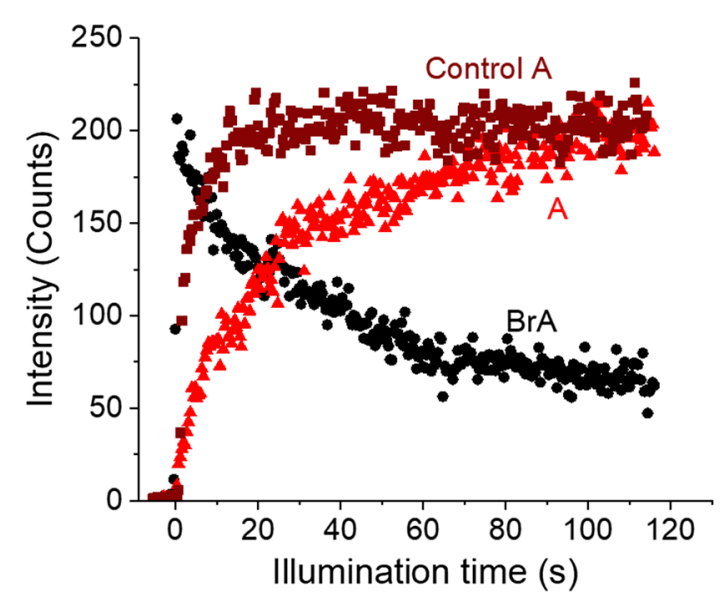

Fig. 5. Intensities of the ring breathing modes of $\mathrm{BrA}$ on AgNPs at $770 \mathrm{~cm}^{-1}$ (black) and A at $739 \mathrm{~cm}^{-1}$ formed under laser illumination (light red) of BrA plotted as a function of the illumination time. The intensity of the ring breathing mode of A on AgNPs as a control sample (dark red). and the concomitant rise of the A peak at $739 \mathrm{~cm}^{-1}$, respectively. After approximately 20 s of illumination, both $\mathrm{A}$ and $\mathrm{BrA}$ contributed equally to the measured signal in the SERS spectra (see Fig. 5).

Additionally, as a control, A has been adsorbed on AgNPs and illuminated with laser light as shown in Figure 5. The Raman intensity at $740 \mathrm{~cm}^{-1}$ due to ring breathing mode of the A signal was monitored. The rise in the signal intensity observed within in the first few seconds of laser illumination might be explained by a charge transfer from the AgNP to the adsorbed A leading to the chemical enhancement of the Raman signal [41]. After the initial signal rise, the signal intensity due to ring breathing mode of A remained constant, indicating that neither the molecules are decomposed nor the plasmonic substrate is modified.

\subsection{Bromocytosine and cytosine}

Raman spectra of $\mathrm{BrC}$ and $\mathrm{C}$ on AgNPs have been recorded under the same measurement conditions as 
Table 2. Raman shifts of NRS and SERS bands of $\mathrm{C}$ and $\mathrm{BrC}$ observed in the present experiment given in $\mathrm{cm}^{-1}$ and assignment of the bands according to references [44] and [43]. $\omega$ : wagging; $\delta$ : in-plane deformation; $\Delta$ : in-plane ring deformation of skeletal atoms; $\gamma$ : out-of-plane deformation; $\Gamma$ : out-of-plane ring deformation of skeletal atoms; $\alpha$ : scissoring; $\tau$ : torsion; t: twisting; $\nu$ : stretching; r: rocking; ring: pyrimidine ring. Atoms are labeled according to Figure 6.

\begin{tabular}{|c|c|c|c|c|c|}
\hline NRS C & SERS C & Assignment [44] & NRS BrC & SERS BrC & Assignment [43] \\
\hline 162 & & & 229 & & \\
\hline 237 & & & 294 & & \\
\hline 407 & & & 312 & 307 & $\delta(\mathrm{C}-\mathrm{Br}),(\Delta(\mathrm{ring}), \delta(\mathrm{NH} 2)$ \\
\hline 448 & 440 & & 408 & & puckering $\mathrm{N} 3+\gamma(\mathrm{NH} 2)$ \\
\hline 540 & 494 & & 428 & 427 & $\gamma(\mathrm{N} 1-\mathrm{CH}=\mathrm{C}),(\Gamma($ ring $), \tau(\mathrm{NH} 2)$ \\
\hline 552 & 565 & $\Delta$ (ring) & 546 & 477 & $\Delta($ ring $)$ mainly in $\mathrm{N} 1, \mathrm{~N} 3+\delta(\mathrm{NH} 2)$ \\
\hline 603 & 605 & $\gamma(\mathrm{C} 2=\mathrm{O})$ & 588 & 580 & $\Delta$ (ring), $\delta(\mathrm{C}=\mathrm{O}), \delta(\mathrm{NH} 2)$ \\
\hline 702 & & $\Gamma($ ring $)$ & & 624 & $\gamma(\mathrm{N} 1-\mathrm{H}), \Gamma($ ring $), \tau(\mathrm{NH} 2)$ \\
\hline 794 & 801 & ring breath & 662 & 681 & $\gamma(\mathrm{N}-\mathrm{CO}-\mathrm{N})$ mainly in $\mathrm{C} 2, \Gamma$ (ring) \\
\hline 896 & & & & 738 & \\
\hline 975 & & & 788 & 802 & $\nu($ ring $), \delta(\mathrm{NH} 2)$ \\
\hline 993 & 1009 & & 867 & & \\
\hline 1014 & 1040 & & 879 & & \\
\hline 1112 & 1135 & & 949 & 953 & $\gamma(\mathrm{C} 6-\mathrm{H})$ \\
\hline 1153 & 1199 & $\Delta($ ring $), \nu(\mathrm{C}-\mathrm{N})$ & 979 & 1009 & $\nu$ (ring) \\
\hline 1252 & 1253 & $\Delta($ ring $), \nu(\mathrm{C}-\mathrm{N})$ & 1064 & 1067 & \\
\hline 1279 & 1310 & $\Delta($ ring $), \nu(\mathrm{C}-\mathrm{N})$ & & 1116 & \\
\hline 1365 & 1368 & $\delta(\mathrm{N} 1-\mathrm{H}, \mathrm{C} 5-\mathrm{H}, \mathrm{C} 6-\mathrm{H})$ & 1236 & 1177 & $\delta(\mathrm{H}-\mathrm{N} 1-\mathrm{C} 6-\mathrm{H}), \nu($ ring $), \delta(\mathrm{NH} 2)$ \\
\hline 1464 & 1429 & $\delta(\mathrm{N} 1-\mathrm{H}, \mathrm{C} 5-\mathrm{H}, \mathrm{C} 6-\mathrm{H})$ & 1283 & 1244 & $\nu(\mathrm{C} 2-\mathrm{N} 3), \nu(\mathrm{CN} 1), \Delta($ ring $), \delta(\mathrm{NH} 2)$ \\
\hline 1537 & 1489 & $\nu(\mathrm{C} 4-\mathrm{N})$ & 1308 & 1308 & $\delta(\mathrm{C}-\mathrm{H}), \nu(\mathrm{CCC}), \delta(\mathrm{N} 1-\mathrm{H})$ \\
\hline 1656 & 1591 & $\delta(\mathrm{NH} 2)$ & & 1340 & \\
\hline \multirow[t]{4}{*}{1694} & 1637 & $\nu(\mathrm{C} 2=\mathrm{O})$ & 1444 & 1467 & $\delta(\mathrm{N} 1-\mathrm{H}), \nu(\mathrm{N}-\mathrm{C} 4), \Delta($ ring $), \delta(\mathrm{NH} 2)$ \\
\hline & & & 1537 & & $\nu(\mathrm{N} 3-\mathrm{C} 4), \nu(\mathrm{N} 1-\mathrm{C}-\mathrm{C}), \tau(\mathrm{NH} 2)$ \\
\hline & & & 1622 & & \\
\hline & & & 1647 & & $\nu(\mathrm{C}=\mathrm{C}), \nu(\mathrm{C}-\mathrm{N}), \tau(\mathrm{NH} 2)$ \\
\hline
\end{tabular}

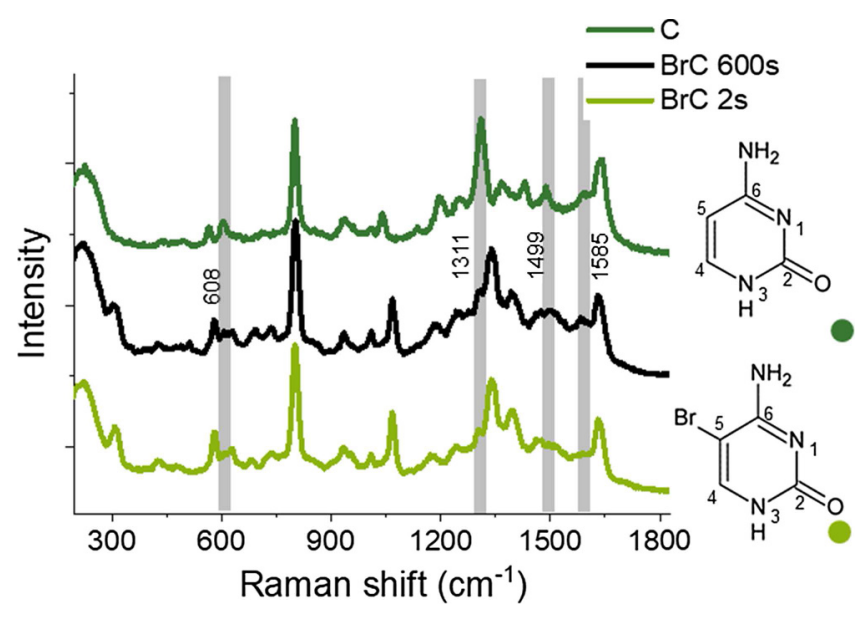

Fig. 6. SERS spectra of BrC adsorbed on AgNPs after $2 \mathrm{~s}$ (light green) and 600s (black) of laser illumination in a confocal Raman microscope. A SERS spectrum of $\mathrm{C}$ on AgNPs (dark green) is shown as a control. Laser wavelength: $532 \mathrm{~nm}$, laser power: $0.05 \mathrm{~mW}$, data acquisition time: $2 \mathrm{~s}$, number accumulations: 3 . The wavenumbers of the marked Raman bands are determined from the BrC spectrum after $600 \mathrm{~s}$ of laser illumination. Molecular structure of $\mathrm{C}$ and $\mathrm{BrC}$ are presented on the right side.

reported for BrA and A in Section 3.1. All observed bands are listed in Table 2 and have been assigned to the vibrational modes of the molecules reported previously by DFT calculations $[42,43]$. It is to be mentioned that the ring breathing modes of $\mathrm{BrC}$ and $\mathrm{C}$ appear at $802 \mathrm{~cm}^{-1}$ and

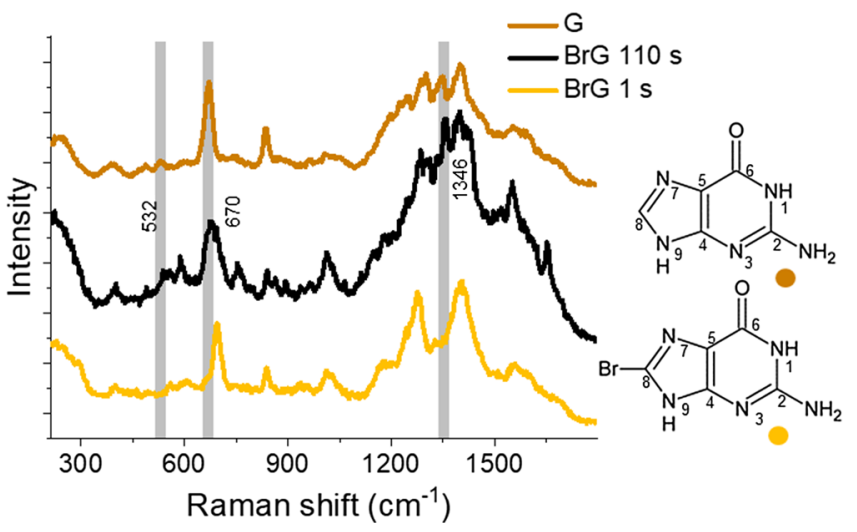

Fig. 7. SERS spectra of BrG adsorbed on AgNPs after $1 \mathrm{~s}$ (yellow) and $110 \mathrm{~s}$ (black) of laser illumination in a confocal Raman microscope. SERS spectrum of G on AgNPs (brown) is shown as a control. Laser wavelength: $532 \mathrm{~nm}$, laser power: $0.05 \mathrm{~mW}$, data acquisition time: $0.4 \mathrm{~s}$, number accumulations: 3. The wavenumbers of the marked Raman bands are determined from the BrG spectrum after $110 \mathrm{~s}$ of laser illumination. Molecular structure of $\mathrm{G}$ and $\mathrm{BrG}$ are presented on the right side.

$801 \mathrm{~cm}^{-1}$, respectively. As a result, the intensity of the Raman signal appears to be constant during the illumination, even if a transformation from $\mathrm{BrC}$ to $\mathrm{C}$ occurs considering comparable Raman cross sections of both molecules. In consequence, the plasmon mediated decomposition of $\mathrm{BrC}$ is more difficult to track compared to $\mathrm{BrA}$, since there is no distinct intense band of $\mathrm{C}$, that does not overlap with 
Table 3. Raman shifts of NRS and SERS bands of G and BrG observed in the present experiment given in $\mathrm{cm}^{-1}$ and assignment of the bands according to reference [45] $\omega$ : wagging; $\delta$ : in-plane deformation; $\Delta$ : in-plane ring deformation of skeletal atoms; $\gamma$ : out-of-plane deformation; $\Gamma$ : out-of-plane ring deformation of skeletal atoms; $\alpha$ : scissoring; $\tau$ : torsion; t: twisting; $\nu$ : stretching; r: rocking; Pyr: pyrimidine; Im: imidazole. Atoms are labeled according to Figure 7.

\begin{tabular}{|c|c|c|c|c|}
\hline NRS G & SERS G & Assignment [45] & NRS BrG & SERS BrG \\
\hline 173 & & & 151 & \\
\hline 208 & & & 180 & \\
\hline 344 & & & 292 & 291 \\
\hline 381 & 390 & $\Delta(\mathrm{C} 2-\mathrm{N} 10)$ & 380 & 399 \\
\hline 404 & & & 414 & 456 \\
\hline 499 & 489 & $\Delta(\mathrm{Pyr})$ & 530 & 492 \\
\hline 552 & 531 & $\Delta(\mathrm{Pyr})$ & 564 & 558 \\
\hline 564 & & & 580 & 606 \\
\hline 609 & 600 & $\Delta(\mathrm{Pyr}), \tau(\mathrm{NH} 2)$ & 675 & 695 \\
\hline 653 & 670 & Breath Pyr & 690 & 748 \\
\hline 697 & 709 & $\Gamma(\mathrm{Pyr}), \gamma(\mathrm{C} 6=\mathrm{O})$ & 775 & 770 \\
\hline 714 & 763 & & 867 & 838 \\
\hline 780 & 794 & & 976 & 951 \\
\hline 850 & 834 & $\omega(\mathrm{NH} 2), \Delta(\mathrm{Pyr}), \Delta(\mathrm{Im})$ & 1053 & 1015 \\
\hline 887 & & & 1171 & 1178 \\
\hline \multirow[t]{2}{*}{943} & 963 & $\Delta(\operatorname{Im})$ & 1189 & \\
\hline & 1010 & & 1213 & \\
\hline 1054 & 1049 & $\nu(\mathrm{N} 1-\mathrm{C} 2, \mathrm{C} 2-\mathrm{N} 10)$ & 1233 & 1276 \\
\hline 1162 & & $\mathrm{r}(\mathrm{NH} 2)$ & 1346 & 1332 \\
\hline 1188 & 1199 & $\mathrm{r}(\mathrm{NH} 2), \delta(\mathrm{N} 1-\mathrm{H}, \mathrm{C} 8-\mathrm{H})$ & 1394 & 1403 \\
\hline 1233 & 1226 & $\nu(\mathrm{C} 8-\mathrm{N} 9)$ & 1435 & \\
\hline 1266 & 1245 & $\delta(\mathrm{C} 8-\mathrm{H}, \mathrm{N} 1-\mathrm{H}), \nu(\mathrm{N} 7-\mathrm{C} 8), \mathrm{r}(\mathrm{NH} 2)$ & 1454 & \\
\hline 1364 & 1293 & $\delta(\mathrm{N} 1-\mathrm{H}, \mathrm{N} 10-\mathrm{H})$ & 1525 & 1497 \\
\hline 1391 & 1346 & $\delta(\mathrm{C} 8-\mathrm{H}, \nu(\mathrm{C} 4-\mathrm{N} 9, \mathrm{C} 5-\mathrm{C} 6, \mathrm{~N} 7-\mathrm{C} 8)$ & 1546 & 1558 \\
\hline 1416 & 1400 & $\delta(\mathrm{N} 1-\mathrm{H}, \mathrm{C} 8-\mathrm{H}), \nu(\mathrm{N} 3-\mathrm{C} 4, \mathrm{C} 4-\mathrm{C} 5, \mathrm{~N} 1-\mathrm{C} 2, \mathrm{~N} 7-\mathrm{C} 8)$ & 1571 & \\
\hline 1470 & & & 1599 & \\
\hline 1553 & 1553 & $\alpha(\mathrm{NH} 2), \nu(\mathrm{C} 2-\mathrm{N} 3, \mathrm{C} 2-\mathrm{N} 10), \delta(\mathrm{N} 1-\mathrm{H})$ & 1671 & \\
\hline 1602 & 1627 & & 1693 & \\
\hline 1683 & 1654 & $\nu(\mathrm{C} 6=\mathrm{O}, \mathrm{C} 5, \mathrm{C} 6, \mathrm{C} 2-\mathrm{N} 3), \delta(\mathrm{N} 1-\mathrm{H})$ & & \\
\hline
\end{tabular}

Raman bands of BrC (see Fig. 6). However, in the irradiated BrC sample new bands at $608 \mathrm{~cm}^{-1}, 1311 \mathrm{~cm}^{-1}$, $1499 \mathrm{~cm}^{-1}$ and $1585 \mathrm{~cm}^{-1}$ are arising, which clearly indicates the formation of $\mathrm{C}$ (see Fig. 6). Compared to the measurements of BrA reported above, only minor changes in the SERS signal of the laser illuminated BrC sample was observed even after six times longer illumination time. Furthermore, the intensities of the new bands assigned to the formation of $\mathrm{C}$ are fluctuating, which may also indicate consecutive reactions of the $\mathrm{C}$ radical. Due to the strong overlap of the $\mathrm{C}$ band with the vibrational bands of $\mathrm{BrC}$ the traceability of the reaction is limited.

\subsection{Bromoguanine and guanine}

Next, the decomposition behavior of $\mathrm{G}$ and $\mathrm{BrG}$ on aggregated AgNPs have been studied. Figure 7 shows the significant change in the SERS spectrum of BrG during ongoing illumination of BrG on AgNPs. This was reflected by decrease in the Raman signal intensity due to ring breathing mode of $\mathrm{BrG}$ at $695 \mathrm{~cm}^{-1}$ and a concomitant rise of a new band at $670 \mathrm{~cm}^{-1}$, which can be assigned to the ring breathing mode of $\mathrm{G}$. In addition, the rising bands at $532 \mathrm{~cm}^{-1}$ and $1346 \mathrm{~cm}^{-1}$ also indicate the formation of $\mathrm{G}$ (see Fig. 7). The observed Raman bands of the $\mathrm{G}$ and $\mathrm{BrG}$ samples from our experimental results have been summarized in Table 3 and the band assignment for $\mathrm{G}$ has been performed by comparing it with val-

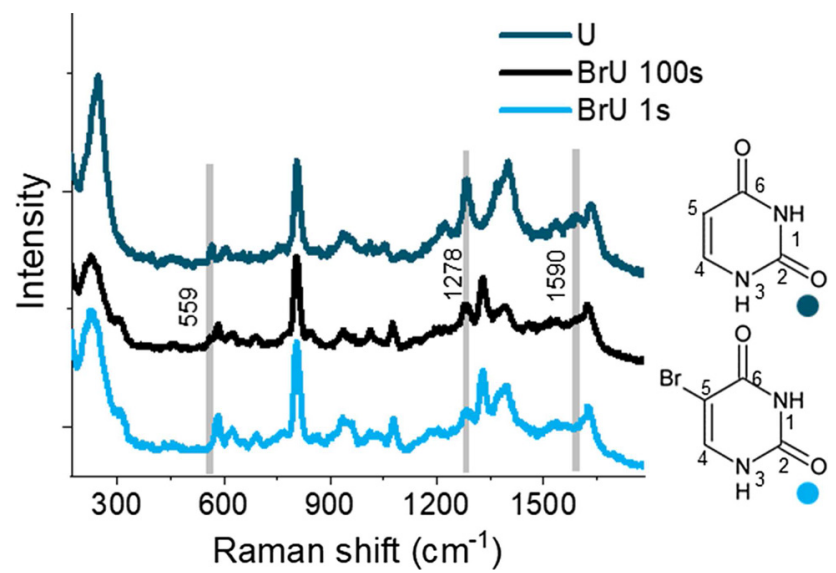

Fig. 8. SERS spectra of BrU adsorbed on AgNPs after $1 \mathrm{~s}$ (light blue) and $100 \mathrm{~s}$ (black) of laser illumination in a confocal Raman microscope. SERS spectrum of U on AgNPs (dark blue) is shown as a control. Laser wavelength: $532 \mathrm{~nm}$, laser power: $0.05 \mathrm{~mW}$, data acquisition time: $0.4 \mathrm{~s}$, number accumulations: 3. The wavenumbers of the marked Raman bands are determined from the BrU spectrum after $100 \mathrm{~s}$ of laser illumination. Molecular structure of $\mathrm{U}$ and $\mathrm{BrU}$ are presented on the right side.

ues reported by [46] in DFT calculations. It is to be noted that no experimental or theoretical Raman data for $\mathrm{BrG}$ has been published so far. 
Table 4. Raman shifts of NRS and SERS bands of $\mathrm{U}$ and BrU observed in the present experiment given in $\mathrm{cm}^{-1}$ and assignment of the bands according to references [46] and [47]. $\omega$ : wagging; $\delta$ : in-plane deformation; $\Delta$ : in-plane ring deformation of skeletal atoms; $\gamma$ : out-of-plane deformation; $\Gamma$ : out-of-plane ring deformation of skeletal atoms; $\alpha$ : scissoring; $\tau$ : torsion; t: twisting; $\nu$ : stretching; r: rocking; ring: pyrimidine ring. Atoms are labeled according to Figure 8.

\begin{tabular}{|c|c|c|c|c|c|}
\hline NRS U & SERS U & Assignment [46] & NRS BrU & SERS BrU & Assignment [47] \\
\hline 401 & 399 & $\Delta$ ring & 144 & & \\
\hline 433 & 455 & $\delta(\mathrm{C} 2=\mathrm{O}, \mathrm{C} 4=\mathrm{O})$ & 155 & & \\
\hline 538 & 566 & $\delta(\operatorname{ring})$ & 207 & & \\
\hline 560 & 598 & $\delta$ (ring) & 305 & & \\
\hline \multirow[t]{2}{*}{581} & 608 & $\delta($ ring $)$ & 428 & 433 & $\delta(\mathrm{CO})+\delta($ ring $)$ \\
\hline & 654 & $\delta$ (ring) & 552 & 583 & $\delta($ ring $)+\delta(\mathrm{CO})$ \\
\hline 736 & 708 & & 614 & 624 & \\
\hline 793 & 806 & Ring breath & 638 & 653 & $\delta($ ring $)+\mathrm{v}(\mathrm{C}-\mathrm{Br})$ \\
\hline 830 & & & & 692 & \\
\hline 868 & & & 751 & 767 & \\
\hline 990 & & & 789 & 806 & ring breathing \\
\hline \multirow[t]{2}{*}{1010} & 1012 & $\delta($ ring $)$ & 848 & & \\
\hline & 1051 & $\delta($ ring $)$ & 949 & 958 & \\
\hline 1104 & 1106 & $\delta(\mathrm{C} 5-\mathrm{H}, \mathrm{C} 6-\mathrm{H})+\nu(\mathrm{C} 5=\mathrm{C} 6, \mathrm{C} 6-\mathrm{N} 1)$ & 1017 & 1010 & $\delta(\mathrm{N} 3-\mathrm{H}, \mathrm{C} 6-\mathrm{H})+\nu(\mathrm{C}-\mathrm{N})$ \\
\hline 1167 & & & 1175 & 1077 & $\nu$ (ring) \\
\hline \multirow[t]{2}{*}{1239} & 1221 & $\delta(\mathrm{N} 1-\mathrm{H}, \mathrm{C} 6-\mathrm{H}, \mathrm{C} 5-\mathrm{H}), \nu(\mathrm{C} 6-\mathrm{N} 1)$ & 1184 & 1202 & $\delta(\mathrm{N} 1-\mathrm{H}, \mathrm{C} 6-\mathrm{H})+\nu($ ring $)$ \\
\hline & 1284 & $\nu(\mathrm{N} 3-\mathrm{C} 4(-\mathrm{C} 4-\mathrm{C} 5-\mathrm{C} 6-\mathrm{N} 1), \delta(\mathrm{N} 1-\mathrm{H}, \mathrm{C} 5-\mathrm{H}, \mathrm{C} 6-\mathrm{H})$ & 1232 & & \\
\hline 1398 & 1394 & $\Delta(\mathrm{C} 6-\mathrm{H}, \mathrm{N} 1-\mathrm{H}, \mathrm{C} 5-\mathrm{H})$ & 1247 & 1288 & $\delta(\mathrm{N} 1-\mathrm{H}, \mathrm{C} 6-\mathrm{H})+\nu($ ring $)$ \\
\hline 1422 & & & 1345 & 1329 & $\delta(\mathrm{C} 6-\mathrm{H})+\nu($ ring $)$ \\
\hline 1461 & & & 1410 & 1394 & $\nu($ ring $)+\delta(\mathrm{N} 1-\mathrm{H})$ \\
\hline 1508 & 1536 & & 1454 & & \\
\hline 1615 & 1591 & $\nu(\mathrm{C} 4=\mathrm{O}, \mathrm{C} 5=\mathrm{C} 6, \mathrm{C} 2=\mathrm{O}), \Delta(\mathrm{N} 1-\mathrm{H}, \mathrm{C} 6-\mathrm{H})$ & 1499 & 1536 & $\nu(\mathrm{C} 5=\mathrm{C} 6)$ \\
\hline 1648 & 1633 & $\nu(\mathrm{C} 2=\mathrm{O})+\nu(\mathrm{C} 4=\mathrm{O}), \delta(\mathrm{N} 3-\mathrm{H})$ & 1622 & 1626 & $\nu(\mathrm{C} 4=\mathrm{O})$ \\
\hline 1717 & & & 1679 & & \\
\hline
\end{tabular}

\subsection{Bromouracil and uracil}

Figure 8 shows the changes recorded in the Raman spectrum during the irradiation of $\mathrm{BrU}$ coated AgNPs. The bands at $559 \mathrm{~cm}^{-1}, 1278 \mathrm{~cm}^{-1}$ and $1590 \mathrm{~cm}^{-1}$ indicate the formation of $U$ (assignment of all SERS bands of $U$ and $\mathrm{BrU}$ are given in Tab. 4). Like for all the nucleobase analogues studied above, we expect to observe a hot electron induced cleavage of the $\mathrm{C}-\mathrm{Br}$ bond in $\mathrm{BrU}$. However, as already observed for the dissociation of $\mathrm{BrC}$ in Section 3.2 the new arising bands have a weak intensity and are often overlapped with the bands of $\mathrm{BrU}$. The ring breathing mode was observed at $806 \mathrm{~cm}^{-1}$ for both of $\mathrm{U}$ and $\mathrm{BrU}$, which makes the simple tracking of the reaction following this Raman mode cumbersome.

\section{Conclusion}

SERS spectra of the four nucleobases and their brominated analogues on AgNPs fractal aggregates have been recorded. The respective assignment of the Raman bands has been done using data from DFT calculations published previously $[39,40,42-47]$. For all four brominated nucleobases the cleavage of the $\mathrm{C}-\mathrm{Br}$ bond has been observed leaving the residual molecule intact under low intensity laser illumination in a Raman microscope. The reaction products have been identified by their vibrational fingerprint in SERS spectrum and could be assigned to the non-brominated nucleobases. The decomposition is most likely to proceed via a dissociative hot electron transfer from the AgNPs to the brominated analogues of nucleobases, although thermal dissociation might also partly contribute to the formation of the reaction products. Additional decomposition pathways have not been detected, however, it needs to be mentioned that the identification of minor changes like hydrogen abstraction during the reaction progress via SERS is challenging. The above mentioned plasmon mediated reactions are of importance in the analysis of SERS spectra of electrophilic molecules in general and especially for analytical SERS applications of DNA, as the spectra of the initially present species need to be distinguished from the spectra of photoproducts generated during the measurement. Importantly, for $\mathrm{BrA}$ and $\mathrm{BrG}$, a rapid dissociation to $\mathrm{A}$ and $\mathrm{G}$ respectively has been observed at low laser powers in our study. The reaction of these purine derivatives can be easily tracked by the ring breathing mode of the molecules. Due to the high signal intensities of these modes and their location in a wavenumber regime without much overlap with other bands, this consequently allows to study the reactions of $\mathrm{BrG}$ and $\mathrm{BrA}$ in more complex systems, e.g. when these molecules are incorporated in a DNA strand. Such more sophisticated experiments will help to evaluate potential applications of electrophilic radiosensitizers in cancer PTT.

Open access funding provided by Project DEAL. This work was supported by the European Research Council (ERC; consolidator grant no. 772752). 


\section{Author contribution statement}

I.B. and R.S. designed the research and conceived the experiments. All measurements and data analysis have been performed by A.D. and R.S. In the preparation of the manuscript all authors were involved. Furthermore, all authors have read and approved the final manuscript.

Open Access This is an open access article distributed under the terms of the Creative Commons Attribution License (http://creativecommons.org/licenses/by/4.0/), which permits unrestricted use, distribution, and reproduction in any medium, provided the original work is properly cited.

\section{References}

1. S. Schlücker, Angew. Chem. Int. Ed. 53, 4756 (2014)

2. A. Barhoumi, D. Zhang, F. Tam, N.J. Halas, J. Am. Chem. Soc. 130, 5523 (2008)

3. E. Garcia-Rico, R.A. Alvarez-Puebla, L. Guerrini, Chem. Soc. Rev. 47, 4909 (2018)

4. C. Muehlethaler, M. Leona, J.R. Lombardi, Anal. Chem. 88, $152(2016)$

5. G.V. Hartland, L.V. Besteiro, P. Johns, A.O. Govorov, ACS Energy Lett. 2, 1641 (2017)

6. M.L. Brongersma, N.J. Halas, P. Nordlander, Nat. Nanotechnol. 10, 25 (2015)

7. C. Clavero, Nat. Photonics 8, 95 (2014)

8. Y. Zhang, S. He, W. Guo, Y. Hu, J. Huang, J.R. Mulcahy, W.D. Wei, Chem. Rev. 118, 2927 (2018).

9. S. Linic, P. Christopher, D.B. Ingram, Nat. Mater. 10, 911 (2011)

10. P. Christopher, H. Xin, S. Linic, Nat. Chem. 3, 467 (2011)

11. M.J. Kale, T. Avanesian, P. Christopher, ACS Catal. 4, 116 (2013)

12. I. Bald, J. Langer, P. Tegeder, O. Ingólfsson, Int. J. Mass Spectrom. 277, 4 (2008)

13. M. Orzol, I. Martin, J. Kocisek, I. Dabkowska, J. Langer, E. Illenberger, Phys. Chem. Chem. Phys. 9, 2643 (2007)

14. I. Dabkowska, H.D. Flosadóttir, M. Orzol, S. Ptasinska, I. Bald, O. Ingólfsson, E. Illenberger, Phys. Chem. Chem. Phys. 11, 5323 (2009)

15. I.I. Fabrikant Phys. Rev. A 76, 269 (2007)

16. L. Sanche, A.D. Bass, P. Ayotte, I.I. Fabrikant, Phys. Rev. Lett. 75, 3568 (1995)

17. R. Schürmann, K. Tanzer, I. Dąbkowska, S. Denifl, I. Bald, J. Phys. Chem. B 121, 5730 (2017)

18. H. Abdoul-Carime, M.A. Huels, F. Brüning, E. Illenberger, L. Sanche, J. Chem. Phys. 113, 2517 (2000)

19. A. Kumar, M.D. Sevilla, J. Phys. Chem. A 121, 4825 (2017)
20. M. Wieczór, P. Wityk, J. Czub, L. Chomicz, J. Rak, Chem. Phys. Lett. 595-596, 133 (2014)

21. L. Chomicz, J. Rak, P. Storoniak, J. Phys. Chem. B 116, $5612(2012)$

22. D. Huber, M. Beikircher, S. Denifl, F. Zappa, S. Matejcik, A. Bacher, V. Grill, T.D. Märk, P. Scheier, J. Chem. Phys. 125, 84304 (2006)

23. S. Denifl, S. Ptasińska, M. Probst, J. Hrušák, P. Scheier, T.D. Märk, J. Phys. Chem. A 108, 6562 (2004)

24. H. Abdoul-Carime, J. Langer, M.A. Huels, E. Illenberger, Eur. Phys. J. D 35, 399 (2005)

25. R. Schürmann, I. Bald, J. Phys. Chem. C 120, 3001 (2016)

26. R. Schürmann, I. Bald, Nanoscale 9, 1951 (2017)

27. R. Schürmann, S. Vogel, K. Ebel, I. Bald, Chem. Eur. J. 24, 10271 (2018)

28. Y. Zheng, L. Sanche, Radiat. Res. 172, 114 (2009)

29. N.S. Abadeer, C.J. Murphy, J. Phys. Chem. C 120, 4691 (2016)

30. C. Zhan, X.-J. Chen, J. Yi, J.-F. Li, D.-Y. Wu, Z.-Q. Tian, Nat. Rev. Chem. 2, 216 (2018)

31. P.C. Lee, D. Meisel, J. Phys. Chem. 86, 3391 (1982)

32. S. Agnihotri, S. Mukherji, S. Mukherji, RSC Adv. 4, 3974 (2014)

33. W. Wenseleers, F. Stellacci, T. Meyer-Friedrichsen, T. Mangel, C.A. Bauer, S.J.K. Pond, S.R. Marder, J.W. Perry, J. Phys. Chem. B 106, 6853 (2002)

34. L. Yu, N. Li, Langmuir 32, 5510 (2016)

35. R. Schürmann, I. Bald, Phys. Chem. Chem. Phys. 19, 10796 (2017)

36. A. Dutta, A. Paul, A. Chattopadhyay, RSC Adv. 6, 82138 (2016)

37. A. Dutta, S. Das, A. Paul, A. Chattopadhyay, J. Nanopart. Res. 17, 8179 (2015)

38. J. Liu, Phys. Chem. Chem. Phys. 14, 10485 (2012)

39. Y.-L. Chen, D.-Y. Wu, Z.-Q. Tian, J. Phys. Chem. A 120, 4049 (2016)

40. R.P. Lopes, R. Valero, J. Tomkinson, M.P.M. Marques, L.A.E. Batista de Carvalho, New J. Chem. 37, 2691 (2013)

41. C. Boerigter, U. Aslam, S. Linic, ACS Nano 10, 6108 (2016)

42. M.A. Palafox, Phys. Sci. Rev. 2, 387 (2017)

43. M.A. Palafox, V.K. Rastogi, S. Kumar, H. Joe, Spectrochim Acta A. 111, 104 (2013)

44. F. Madzharova, Z. Heiner, M. Gühlke, J. Kneipp, J. Phys. Chem. C 120, 15415 (2016)

45. B. Giese, D. McNaughton, Phys. Chem. Chem. Phys. 4, $5171(2002)$

46. B. Giese, D. McNaughton, J. Phys. Chem. B 106, 1461 (2002)

47. V.K. Rastogi, M.A. Palafox, L. Mittal, N. Peica, W. Kiefer, K. Lang, S.P. Ojha, J. Raman Spectrosc. 38, 1227 (2007) 